\title{
Estimation of lung growth using computed tomography
}

\author{
P.A. de Jong*, Y. Nakano", M.H. Lequin\#, P.J. Merkus*, H.A. Tiddens*, J.C. Hogg ${ }^{\mp}$, H.O. Coxson ${ }^{+}$
}

Estimation of lung growth using computed tomography. P.A. de Jong, Y. Nakano, M.H. Lequin, P.J. Merkus, H.A. Tiddens, J.C. Hogg, H.O. Coxson. C)ERS Journals Ltd 2003.

ABSTRACT: Anatomical studies suggest that normal lungs grow by rapid alveolar addition until about 2 yrs of age followed by a gradual increase in alveolar dimensions.

The aim of this study was to examine the hypothesis that normal lung growth can be monitored by computed tomography (CT). Therefore, the gas volume per gram of lung tissue was estimated from measurements of lung density obtained from CT scans performed on children throughout the growth period.

CT scans were performed on 17 males and 18 females, ranging in age from 15 days17.6 yrs. CT-measured lung weight was correlated with predicted post mortem values and CT measured gas volume with predicted values of functional residual capacity. The median value for lung expansion was $1.86 \mathrm{~mL} \cdot \mathrm{g}^{-1}$ at 15 days, decreased to $0.79 \mathrm{~mL} \cdot \mathrm{g}^{-1}$ by 2 yrs and then increased steadily to $5.07 \mathrm{~mL} \cdot \mathrm{g}^{-1}$ at $17 \mathrm{yrs}$.

Computed tomography scans can be used to estimate lung weight, gas volume and expansion of normal lungs during the growth period. The increase in the lung expansion after the age of 2 yrs suggests progressive alveolar expansion with increasing lung volume.

Eur Respir J 2003; 22: 235-238.
*Dept of Paediatric Pulmonology and ${ }^{\#}$ Dept of Paediatric Radiology, Sophia Children's Hospital, Erasmus Medical Centre Rotterdam, Rotterdam, the Netherlands. University of British Columbia, McDonald Research Laboratory and iCAPTURE Centre, St Paul's Hospital and ${ }^{+}$Dept of Radiology, Vancouver Hospital and Health Science Centre, Vancouver, BC, Canada.

Correspondence: H.O. Coxson, Vancouver Hospital and Health Science Centre, Dept of Radiology, 855 West 12 th Avenue, Vancouver, BC Canada, V5Z 1 M9.

Fax: 16048754319

E-mail: hcoxson@vanhosp.bc.ca

Keywords: Computed tomography, lung development, normal lung, quantitative computed tomography analysis

Received: September 302002

Accepted after revision: February 262003

P.A. de Jong was supported by a fellowship from the "Gerrit Jan Mulder Stichting", Erasmus University, Erasmus Medical Centre Rotterdam, Rotterdam, the Netherlands. H. Coxson is a Parker B. Francis Fellow in Pulmonary Research.
Several reports have shown that only between one-third and one-half of the number of alveoli in the human lung are present at birth [1-3]. This number increases rapidly after birth by a process of septation of the primary saccules and reaches adult values between 1.5-2 yrs of age, and is certainly finished by 8 yrs [1-3]. After this process is completed, the number of alveoli remains constant and the lung continues to grow by increasing the dimensions of all of the lung structures. The small conducting airways that are completely surrounded by alveoli increase their dimensions in a similar fashion, resulting in a substantial increase in peripheral airway conductance around 2 yrs because flow increases in proportion to the forth power of the change in their radius [4]. Direct measurement of airway conductance suggests a rapid increase in peripheral airway conductance at $\sim 5$ yrs of age when alveolar addition slows down and linear dimensions of the lung begin to increase. Lung distension after the period of rapid alveolar addition also increases due to changes in the mechanical properties of the chest wall. These changes result in a relative underdistension of the lung at $<8$ yrs of age and a relative overdistension thereafter $[5,6]$.

The present study was designed to determine if quantitative measurements of computed tomography (CT) scans could measure normal lung development. Furthermore, if CT scans

For editorial comments see page 195. can be used to monitor normal lung growth they may be useful in assessing the effect of chronic lung disease on lung growth.

\section{Methods}

\section{Subjects}

All thoracic CT scans performed at Sophia Children's Hospital (Rotterdam, the Netherlands) between 1998-2001 that were reported as normal by radiologists were included in the study. The study was approved by the ethical committee of Sophia Children's Hospital (Rotterdam, the Netherlands).

\section{Computed tomography scans}

The examinations were all performed on a GE Prospeed SX CT scanner (General Electric Medical Systems, Milwaukee, WI, USA) and the images were archived in DICOM (Digital Imaging and Communications in Medicine) format. The CT scans were performed in the supine position at full-suspended inspiration from age 6 yrs and during quiet breathing for the younger children. Three subjects had axial CT scans with $1-\mathrm{mm}$ thick slices at 10-mm intervals (ages of 11, 12 and $17 \mathrm{yrs})$. The other subjects had spiral CT scans with slice 
thicknesses ranging 3-10 mm. Field of view ranged $25-35 \mathrm{~cm}$, and beam current and potential 130-250 mA and 120-140 kV. The images were reconstructed with a standard reconstruction algorithm.

\section{Computed tomography analysis}

The CT scans were transferred to the iCAPTURE Centre/ McDonald Research Laboratory (Vancouver, BC, Canada) and analysed using a method described previously [6, 7]. Briefly, this program uses the voxel dimensions to calculate lung volume and the x-ray attenuation values of the lung to estimate lung density. Lung weight, in grams, is calculated by multiplying the lung density by the volume. Lung expansion, in millilitres of gas per gram of tissue, is calculated by subtracting the inverse of the density of tissue (assumed to be $1.065 \mathrm{~g} \cdot \mathrm{mL}^{-1}$ ) from the inverse of the CT-measured lung density $[7,8]$. CT-estimated lung weight was compared to previously reported post mortem values from children with normal lungs [9]. CT-determined gas volume was compared to predicted normal values for functional residual capacity (FRC) using equations for children of various body lengths. FRC was measured in the supine position in children aged $0-6$ yrs [10] and in the sitting position in the children aged $\geqslant 6$ yrs [11]. CT-determined gas volume was also compared to published values of total lung capacity (TLC) for children with a body length $<115 \mathrm{~cm} \mathrm{[3]} \mathrm{and} \mathrm{to} \mathrm{predicted} \mathrm{values} \mathrm{for}$ children with a body length $>115 \mathrm{~cm}$ [11]. The values for alveolar number at each body length, calculated separately for both males and females using data from THURLBECK [3], were compared to the CT-determined lung expansion in $\mathrm{mm}$ gas $\cdot \mathrm{g}^{-1}$ tissue at the same body length.

\section{Statistics}

Spearman's correlation was used to compare CT-measured lung weight to predicted lung weight and CT-measured gas volume to predicted FRC and TLC.

\section{Results}

The CT scans from 17 male and 18 female children, ranging in age from 15 days-17.6 yrs were examined in this study. Twenty-three had primary tumours outside the lung (lymphoma $(n=9)$, Wilms tumour $(n=3)$, osteosarcoma $(n=4)$, rabdomyosarcoma $(n=3)$, hepatoblastoma $(n=2)$, Ewing sarcoma $(\mathrm{n}=1)$, melanoma $(\mathrm{n}=1))$, where the scans were performed to rule out lung metastasis. The remaining scans were performed for suspected malignancies $(n=2)$, dysphagia $(n=1)$, haemoptysis $(n=2)$, to assess lung damage following infections $(n=3)$ and for a variety of other reasons $(n=4)$.

Sex, age, height, weight of the subjects and the CT estimates of gas volume, weight, mean volume of $\mathrm{gas}^{-\mathrm{g}^{-1}}$ tissue and predicted alveolar numbers of the subjects' lungs are shown in table 1 . The CT-measured lung weight compares favourably to published post mortem values for children with a body length of $\leqslant 140 \mathrm{~cm}$, which corresponds to $12 \mathrm{yrs}$ of age [9]; both are shown as a function of body length in figure 1. There was a positive correlation (Spearman's correlation coefficient $=0.91, \mathrm{p}<0.0001$ ) between the CT-measured lung weight and published post mortem values.

CT-measured gas volume compared favourably to predicted values for FRC, especially for children $<10$ yrs (body length of $135 \mathrm{~cm}$ ). The gas volume of the older children tended to be above FRC during the scanning procedure (fig. 2). The
Table 1.-Patient characteristics

\begin{tabular}{lcccc}
\hline & Subjects $\mathrm{n}$ & Min. & Max. & Mean \pm SD \\
\hline Age yrs & 35 & 0.04 & 17.6 & $8.9 \pm 5.7$ \\
Height cm & 35 & 54 & 179 & $132.7 \pm 37.5$ \\
Weight kg & 35 & 2.7 & 91.5 & $35.2 \pm 22.7$ \\
$\begin{array}{l}\text { CT estimates } \\
\quad \text { Gas volume mL }\end{array}$ & 35 & 86 & 5061 & $1489 \pm 1289$ \\
$\quad$ Lung expansion & 35 & 0.79 & 5.07 & $2.65 \pm 1.23$ \\
$\quad$ mL.g & & & & \\
$\quad$ Lung weight g & 35 & 45 & 1001 & $452 \pm 272$ \\
$\quad \begin{array}{l}\text { Alveolar number } \\
\quad \text { male } \times 10^{6 \#}\end{array}$ & 17 & 112.15 & 491.29 & $419.19 \pm 86.22$ \\
$\quad \begin{array}{l}\text { Alveolar number } \\
\quad \text { female } \times 10^{6 \#}\end{array}$ & 18 & 93.49 & 428.55 & $364.83 \pm 76.20$ \\
$\quad$
\end{tabular}

Min.: minimum; Max.: maximum; CT: computed tomography. $\mathrm{n}=35,17$ males and 18 females. ${ }^{\#}$ : alveolar numbers shown are predicted post mortem data from [3].

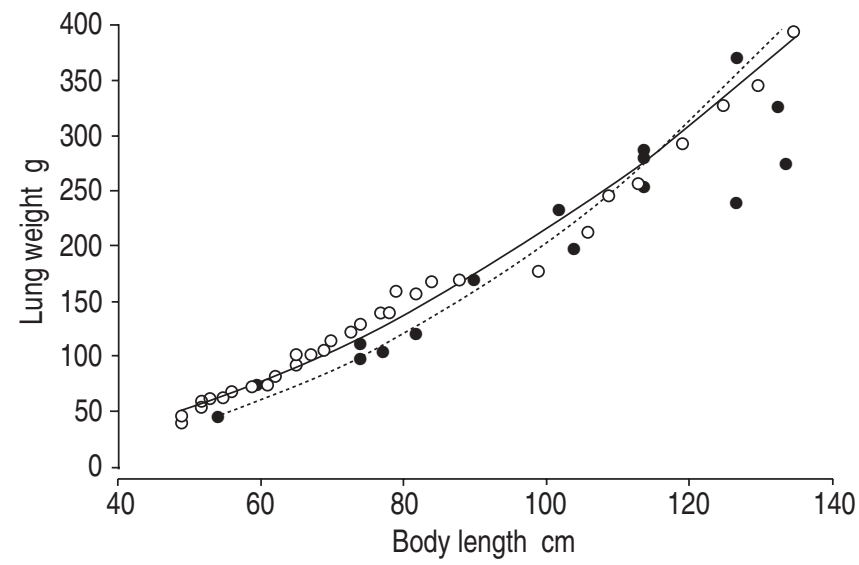

Fig. 1.-Computed-tomography estimated normal lung weight ( $\bullet$, ---) compared with published post mortem normal lung weight $(\bigcirc,-)$.

Spearman's correlation coefficient for the relationship between CT-measured gas volume and predicted values for FRC over the total age range was $0.90(\mathrm{p}<0.0001)$.

A comparison of published values for the total number of alveoli to the mean values of lung expansion $\cdot \mathrm{g}^{-1}$ lung at the same body length, for both males and females, is shown in

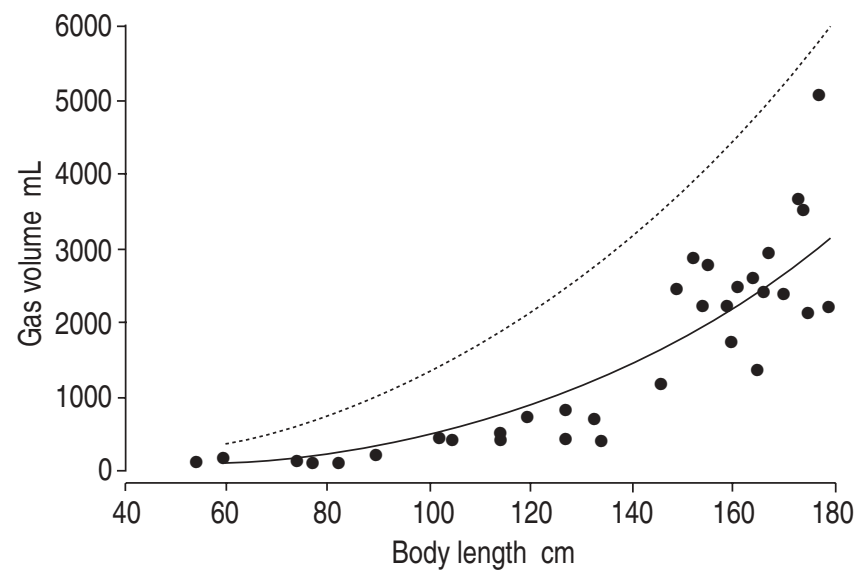

Fig. 2.-Computed-tomography estimated gas volume of the lung ( compared with predicted functional residual volume $(-)$ and predicted total lung capacity (----) 


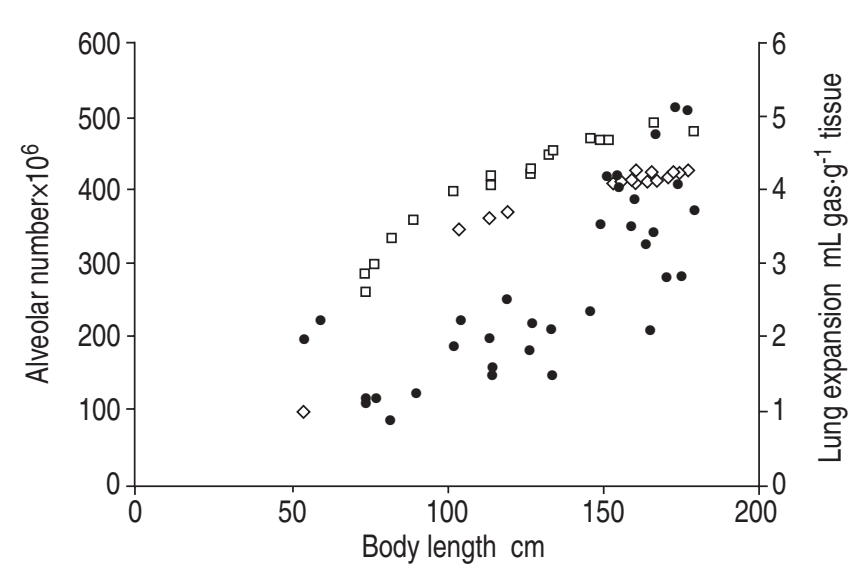

Fig. 3.-Computed-tomography estimated lung expansion published post mortem alveolar numbers for males ( $\square$ ) and females $(\diamond) . \mathrm{R}^{2}=0.43, \mathrm{p}=0.01$.

figure 3. These data show an initial decrease of the lung volume $\cdot \mathrm{g}^{-1}$ tissue between birth and the first year (body lengths $<85 \mathrm{~cm}$ ), followed by a plateau and then a progressive increase. The gas volumes of the two youngest cases (both female) were 47 and $59 \%$ of TLC, respectively.

\section{Discussion}

Previous studies have shown that quantitative measurements of CT scans can quantify the changes in lung tissue associated with chronic lung disease. The present study shows that the CT scan can be used to estimate the lung weight and gas volume in children with normal lungs. The CT measurements of total lung weight, volume and expansion reported here compare favourably to published values of post mortem lung weight [9] and predicted gas volume at FRC in children.

Previous anatomical studies have shown that the number of alveoli increase rapidly following birth. As the added alveoli are a uniform size the current authors postulated that the divisions of existing airspace into smaller units would cause the gas volume $\cdot \mathrm{g}^{-1}$ of tissue to fall. This hypothesis is supported by the data showing a decline in gas volume $\cdot \mathrm{g}^{-1}$ tissue from birth to 2 yrs of age. This decrease in lung expansion between birth and 2 yrs of age is consistent with the rapid addition of alveolar tissue by septation of growing alveoli and larger structures (possibly primary saccules) to form mature respiratory bronchioles, alveolar ducts and sacs [3]. In the current study, since there is only data on two very young patients, the initial decline could be due to other reasons such as relatively large airspaces in these subjects or chance. However, since there is no pathological verification of the lung structure and since the data is consistent with published results, the current authors think that this initial decline in lung expansion is due to the septation process. The subsequent increase in gas volume $\cdot \mathrm{g}^{-1}$ of tissue from age $2-8 \mathrm{yrs}$ probably results from a combination of increased alveolar size and increased outward recoil of the chest wall, which leads to an increased FRC [5, 6].

While it has been shown that young males have more alveoli than young females (fig. 3) [3], the increase in alveolar number with age follows the same trend in both sexes and, therefore, it is unlikely that sex differences are responsible for the initial decline in lung expansion.

In this study, the CT measurements of lung weight for the subjects were compared to predicted values derived from the autopsy studies of COPPOLETTA and WOLBACH [9]. These investigators measured the weight of the vital organs of children between birth and 12 yrs of age in relation to body length using $>1,000$ autopsy records. Comparison of the CT measurements of lung weight for the present subjects to the values predicted for their body length show excellent agreement, indicating that lung weight can be accurately measured using a CT scan performed during the growth period. Although it can be argued that it is hard to compare the results of data on children obtained in the 1930s with children of today, these are the only values that are available for analysis.

The results presented here also show that CT scans performed on children $\leqslant 10$ yrs are obtained at gas volumes that are close to FRC. Older children appear to have inflation levels somewhere between FRC and TLC, indicating that their CT scans were performed after a breath of variable size. The fact that the CT scans were consistently performed close to FRC $\leqslant 10$ yrs indicates that the observed decline in lung expansion between birth and 2 yrs of age can be attributed to an addition of new alveoli. After the period of rapid alveolar addition is complete the gradual expansion in gas volume $\cdot \mathrm{g}^{-1}$ lung is consistent with expansion in the size of alveoli in combination with a gradual increase in FRC due to changes in the mechanical properties of the lung and chest wall $[5,6]$.

This study has some limitations. As mentioned above, the authors do not have any direct pathological validation of the measurements in these subjects. They have, therefore, had to rely on published data to compare results. However, the current data did correlate well with the other previously published data and the authors propose that while this may weaken the study it does not invalidate it. The measurement of lung expansion from CT is critically dependent on the lung volume at which the scan is performed. Therefore, in this study, lung volume was measured on the scans and this volume was related to the predicted values for FRC. The technique used to make the prediction equations is different for the children aged $<6$ yrs [10] compared to the older children [11]. BAR-YISHAY et al. [10] measured FRC in the supine position, ZAPLETAL et al. [11] measured FRC in the sitting position. This results in higher values for FRC in the older children. In addition, the CT scanning technique was different for the children aged $<6$ yrs compared to the older children and the big breath method in the older children results in higher long volumes during the scanning procedure compared to the quiet breathing of the younger children. The exact effect of these errors are not known, however, the observed decline in lung expansion before the 2 yrs cannot be contributed to these errors since the scanning technique and FRC prediction is similar for children aged $<6$ yrs.

In conclusion, it has been shown that quantitative measurements of normal lung development can be made using computed tomography scans. The authors propose that the computed tomography scan can be used as a relatively noninvasive tool to provide valuable information about normal lung growth and the pathogenesis of lung disease.

\footnotetext{
Acknowledgements. The authors would like to thank K. Whittall for his invaluable expertise with the computer algorithms and P. Paré for his support.
}

\section{References}

1. Zeltner TB, Caduff JH, Gehr P, Pfenninger J, Burri PH. The postnatal development and growth of the human lung. I. Morphometry Respir Physiol 1987; 67: 247-267.

2. Hislop AA, Wigglesworth JS, Desai R. Alveolar development in the human fetus and infant. Early Hum Dev 1986; 13: $1-11$. 
3. Thurlbeck WM. Postnatal human lung growth. Thorax 1982; 37: 465-571.

4. Hogg JC, Williams J, Richardson JB, Macklem PT, Thurlbeck WM. Age as a factor in the distribution of lower-airway conductance and in the pathologic anatomy of obstructive lung disease. N Engl J Med 1970; 282: 1283-1287.

5. Taussig LM, Helms PJ. Basic Physiology. In: Stocks J, Sly PD, Tepper RS, Morgan WJ, eds. Infant Respiratory Function Testing. New York, Wiley-Liss, 1996; pp. 2-15.

6. Mansell AL, Bryan AC, Levison H. Relationship of lung recoil to lung volume and max expiratory flow in normal children. J Appl Physiol 1977; 42: 817-823.

7. Coxson HO, Rogers RM, Whittall KP, et al. A quantifica- tion of the lung surface area in emphysema using computed tomography. Am J Respir Crit Care Med 1999; 159: 851-856.

8. Coxson HO, Mayo JR, Behzad H, et al. Measurement of lung expansion with computed tomography and comparison with quantitative histology. J Appl Physiol 1995; 79: 1525-1530.

9. Coppoletta JM, Wolbach SB. Body length and organ weights of infants and children. J Path 1933; 9: 55-70.

10. Bar-Yishay E, Shulman DL, Beardsmore CS, Godfrey S. Functional residual capacity in healthy preschool children lying supine. Am Rev Respir Dis 1987; 135: 954-956.

11. Zapletal A, Samanek M, Paul T. Lung function in children and adolescents: methods, reference values. First ed. Basel, Karger, 1987. 